\title{
ACESSO INDIVIDUAL E COLETIVO DE MORADORES DE FAVELAS À JUSTIÇA
}

\section{Rafaela Selem Moreira Gisele Cittadino}

\section{Introdução}

A Constituição de 1988, símbolo da redemocratização brasileira, foi responsável pela ampliação do rol de direitos não só civis, como também políticos, econômicos, sociais e culturais, entre outros, como os chamados direitos de terceira geração (Santos, 2008). Alguns acadêmicos acreditam que após a promulgação da Constituição Federal de 1988 profundas transformaçôes foram impulsionadas para democratização do Estado e da sociedade (Verbicaro, 2008). Este pensamento é acompanhado da crença de que o Judiciário, neste cenário, protagoniza papel importante uma vez que o agente catalisador da democratização seria uma norma: a Constituição Federal. Nesse sentido, a democratização do Estado e da sociedade seria incrementada com a participação do Judiciário que, por meio de decisões

Artigo recebido em 05/11/2011

Aprovado em 21/11/2012 judiciais, daria materialidade a princípios e garantias constitucionais. Outros (Faria, 1989b; Santos, 2008) acreditam que o Judiciário só poderia impulsionar a democratização da cidade e da sociedade na medida em que o acesso a ele (Judiciário) fosse praticado por todos os cidadãos de maneira igualmente democrática. Deste modo, seria inviável falar em democratização da justiça fora do contexto de uma democratização que inclui o Estado e a sociedade (Santos, 2008). Enfim, em uma sociedade marcadamente desigual, como falar em democracia? Apesar dos questionamentos, há o reconhecimento de que apesar da distância que separa os direitos constitucionalmente positivados das práticas sociais e políticas públicas, cada vez menos as vítimas de violações "se limitariam a chorar na exclusão" (Santos, 2008, p.10). Cada vez mais os pobres urbanos estariam conscientes da sua situação de excluídos e com isso estariam cada vez mais questionando impunidades e demandando por serem ouvidos nos tribunais. 
Segundo Santos (2008), a ampliação de direitos e garantias positivados na Constituição de 1988 tenderia a aumentar a expectativa dos cidadãos de verem seus direitos efetivados "de forma que, a execução deficiente ou inexistente de muitas politicas sociais pode transformar-se num motivo de recurso aos tribunais" (Santos, 2008, p.18). Na medida em que a via judicial surge como alternativa para se alcançar direitos quando o "Estado Intervencionista" (Santos, 2008, p.19) não consegue promover políticas sociais capazes de distribuí-los, os tribunais passariam a assumir novo protagonismo: o papel de distribuir direitos (Santos, 2008). Segundo Santos (2008), a incapacidade da administração pública de "dar conta" da nova demanda social por direitos, ora amparada na Constituição Federal, levaria a um deslocamento de legitimidade do Estado dos poderes Executivo e Legislativo para o Poder Judiciário. "Esse movimento leva a que se criem expectativas positivas elevadas a respeito do sistema judiciário, esperando-se que resolva os problemas que o sistema politico não consegue resolver". (Santos, 2008, p. 21). Neste sentido, na medida em que as pessoas passam a ter mais consciência de direitos, passariam também a recorrer mais aos tribunais para protegerem ou exigirem a sua efetiva execução (Santos, 2008, p. 19).

Com base nessa discussão teórica, formulamos nossa hipótese e a seguinte pergunta experimental: "Se todo esse movimento de deslocamento de legitimidade do sistema político para o Judiciário na busca da efetivação de direitos está acontecendo, o Judiciário estatal deveria estar, cada vez mais, sendo demandado por indivíduos e grupos sociais desprivilegiados economicamente, ou seja, no caso da cidade do Rio de Janeiro, por moradores de favelas e periferias da cidade”. Neste caso, nosso questionamento seguiria com a seguinte indagação: "estaria o Tribunal de Justiça do Estado do Rio de Janeiro atendendo as necessidades desses demandantes, efetivamente ocupando espaços politicamente decisivos na vida dos cidadãos pobres e alienados por gerações da institucionalidade democrática?".

\section{Material e Métodos}

Essa investigação foi realizada em duas etapas: (1) levantamento de dados acerca do contexto ur- bano discutido: favelas cariocas; (2) levantamento de dados no Tribunal de Justiça do Estado do Rio de Janeiro (TJRJ) sobre demandas judiciais relacionadas com as favelas ou seus moradores.

\section{Levantamento de dados acerca do contexto urbano discutido: favela carioca}

O levantamento do contexto das favelas cariocas foi realizado com base em duas perspectivas: (1.1) temporal, com o levantamento da história das favelas na cidade do Rio de Janeiro; (1.2) espacial, com a contextualização recente das favelas na cidade, agregando informações sobre a variação das características das favelas nas diferentes áreas da cidade.

\section{Levantamento histórico}

O levantamento histórico das favelas na cidade do Rio de Janeiro foi empreendido com base em trabalho de síntese de fontes secundárias de informação - livros e artigos. Nesse trabalho nos concentramos em analisar a favela carioca de uma maneira abrangente, sob a perspectiva exclusivamente temporal. (Santos, 1988; Burgos, 1999; Zaluar e Alvito, 1999; Ribeiro, 2001; Cezar, 2002; Abramo, 2003; Pandolfi e Gryszpan, 2003; Perlman, 2003; Besserman e Cavalliere, 2004; Valladares, 2005; Cavallieri e Lopes, 2006; Moreira, 2006, Bauman, 2009).

\section{Contextualização recente}

A contextualização recente das favelas na cidade do Rio de Janeiro foi feita com base no cruzamento de dados primários: comparando a evolução da natalidade e expansão territorial em favelas de diferentes áreas da cidade. (Cezar, 2002; Abramo, 2003; Pandolfi e Gryszpan, 2003; Perlman, 2003; Besserman e Cavalliere, 2004; Valladares, 2005; Cavallieri e Lopes, 2006; Moreira, 2006; Cavalliere e Lopes, 2008; Cavalcanti, 2009; Vial e Cavallieri, 2009; Neri, 2010; Viva-Rio, 2010). Depois de descrito, o cenário recente do crescimento demográfico e territorial das favelas cariocas foi analisado em relação aos diferentes índices de desenvolvimento 
sociais apresentados pelas diferentes áreas da cidade do Rio de Janeiro ${ }^{1}$. Nesse cruzamento, traçamos ainda um paralelo entre esses diferentes índices de desenvolvimento social e as variações na atuação do Estado e da sociedade civil nas favelas em diferentes áreas da cidade (Viva-Rio, 2010; Observatório de Favelas, 2010). Essa etapa da pesquisa contou ainda com observações em campo por meio de visitas às comunidades da Rocinha e Complexo da Maré localizadas nas Zonas Sul e Norte do município do Rio de Janeiro ${ }^{2}$.

\section{Levantamento de dados no Tribunal de Justiça do} Estado do Rio de Janeiro (TJRJ) sobre demandas judiciais relacionadas com as favelas ou seus moradores

Após exame da realidade das favelas na cidade do Rio de Janeiro, procedemos a análise da prática do Tribunal de Justiça do Estado do Rio de Janeiro por meio de demandas judiciais formuladas por moradores de favelas e ainda demandas que visavam discutir o fenômeno da favela, ainda que não propostas por moradores de favelas. Essa investigação foi realizada também em duas etapas. (2.1) A primeira etapa visou levantar o acesso da favela e seus moradores ao TJRJ ao longo do tempo; (2.2) A segunda visou levantar a variação no acesso da favela e seus moradores ao TJRJ nos diferentes espaços urbanos desta cidade.

\section{Acesso da favela e seus moradores ao TJRJ ao longo do tempo}

Para levantamento do acesso da favela e seus moradores ao TJRJ realizamos pesquisa no acervo jurisprudencial cível ${ }^{3}$ disponível no website do Tribunal de Justiça do Estado do Rio de Janeiro (TJRJ) dentro do período de 1980 a 2009 . Este período foi dividido, para fins de análise, em três: de 1980 a 1989; de 1990 a 1999; e de 2000 a 2009. A palavra- chave utilizada na busca jurisprudencial foi: "favela"4

Existe mais de um motivo para a escolha dos anos "1980" para iniciar nosso levantamento jurisprudencial. Além do fato de a democratização do Brasil e a promulgação da Constituição atualmente em vigor terem ocorrido neste período, a partir do final dos anos de 1980, o sistema judicial adquiriu forte proeminência em muitos países latino-americanos recebendo, desde então, muitos investimentos financeiros (Santos, 2008). Os anos de 1980, portanto, gera em muitos estudiosos uma expectativa positiva no que tange à distribuição de direitos e democratização do país. Por este motivo, nossa pesquisa se inicia nos anos de 1980. Ao iniciarmos o levantamento jurisprudencial, no entanto, verificamos que não há qualquer julgado no TJRJ que contenha a palavra "favela" anterior aos anos de 1980. Deste modo, mesmo que tivéssemos a intenção de abranger um período temporal maior, não encontraríamos qualquer julgado.

Quanto ao método de análise do material levantando no website do TJRJ, optamos por realizar análise quantitativa do cabeçalho das decisóes judiciais e quali-quantitativa ${ }^{5}$ da ementa dessas decisões.

Para a análise quantitativa do cabeçalho dos julgados, foram utilizadas as seguintes categorias analíticas primárias: (1) ano do recurso, (2) tipo de recurso, (3) ano do processo originário do qual o recurso é desdobramento (4) ano de julgamento do recurso, e (5) o desembargador que julgou o recurso; e o seguinte item presente na ementa dos julgados: (6) se foi mencionada a Constituição Federal de 1988 na decisão do Tribunal de Justiça.

Além dessas categorias analíticas primárias, criamos uma categoria secundária: "tempo de duração da demanda". Para isso calculamos o tempo que as demandas duravam desde o ano de propositura da ação inicial (item " 3 ") até o ano de julgamento do recurso (item “4”).

Para a análise quali-quantitativa das ementas dos julgados utilizamos as seguintes categorias ${ }^{6}$ : (1) autor da demanda no processo de origem, (2) réu da demanda no processo de origem, (3) abrangência da demanda - se de natureza individual ou coletiva, (4) local onde se localiza o episódio que está sendo discutido em juízo - se foi na favela ou fora dela, (5) a roupagem jurídica que a demanda recebera como ação originária ${ }^{7},(6)$ o objeto jurídico - ou seja, o bem juridicamente tutelado na demanda; (7) o objeto material ${ }^{8}$ - os interesses do mundo real em jogo na demanda, para além dos interesses juridicamente tutelados e, (8) o tipo de argumento usado pelo TJRJ para fundamentar sua decisão - se exclusivamente jurídico ou também 
político e social e, (9) a presença ou não de ativismo judicial na decisão.

No levantamento jurisprudencial foram encontrados, entre 1980 e 2009, 171 registros de decisões judiciais do TJRJ que continham em sua ementa a palavra "favela". Com base nesse levantamento, realizamos uma triagem com o objetivo de filtrar um espaço amostral que contivesse apenas as decisões judiciais que efetivamente discutiam o fenômeno social da favela carioca ou que representassem demandas de moradores de comunidades faveladas. Com esse critério, analisamos o conteúdo de todas as 171 ementas de decisões judiciais e, partir dessa triagem, descartamos 18 julgados de nossa amostra. Além disso, das 163 ementas restantes, foram detectados e excluídos três julgados que apareciam de forma duplicada. Com base nessa triagem, o "n" amostral passou de 171 para 150 registros de decisões judiciais?.

Os 150 julgados foram divididos em três grupos, "anos de 1980" (entre 1980 e 1989); "anos de 1990" (entre 1990 e 1999) e "últimos dez anos" (entre 2000 e 2009). Vale registrar que essa divisão de julgados por grupos levou em consideração $\mathrm{o}$ ano de propositura da ação incial que deu origem ao recurso julgado pelo TJRJ.

De maneira complementar, utilizamos ainda de instrumentos de pesquisa qualitativos como entrevistas e observação. As entrevistas foram realizadas com base em questionários semiestruturados administrados a advogados e demais profissionais liberais integrantes da Renap (Rede de Advogados Populares) em conversas presenciais. Ao todo, foram entrevistados três advogados populares e um historiador que atuam e/ou atuaram na Renap. As observações in loco ocorreram no complexo de favelas da Maré, bem como na favela da Rocinha ao longo do ano de 2010.

\section{Variação no acesso da favela e seus moradores ao TJRJ nos diferentes espaços urbanos desta cidade}

Esta análise agrega perspectiva espacial a este trabalho no que tange as variações do acesso das favelas e de seus moradores ao TJRJ nas diferentes áreas da cidade do Rio de Janeiro.

Para isso, realizamos levantamento das três maiores favelas (em área), das três mais populosas favelas e das três mais antigas favelas da cidade em cada uma das cinco áreas de planejamento municipal - AP 1: Centro; AP 2: Zona Sul; AP 3: Zona Norte; AP 4: Barra da Tijuca e Jacarepaguá; AP 5: Zona Oeste. ${ }^{10}$. Optamos pela seleção das três maiores favelas em área por ser a medição mais atualizada disponível ${ }^{11}$.

Além disso, as três maiores favelas em área, em 2008, correspondem também às favelas que, segundo o último senso do IBGE em 2000, eram também as mais populosas. Por fim, a maior parte das favelas selecionadas corresponde às ocupações mais antigas em suas respectivas áreas de planejamento (APs).

Com base no nome de cada uma dessas comunidades ${ }^{12}$, realizamos nova busca jurisprudencial no website do Tribunal de Justiça do Estado do Rio de Janeiro. Os critérios utilizados para esse levantamento foram os mesmos utilizados no item " 2.1 "13. Os principais resultados obtidos a partir desse trabalho de levantamento e análise serão então descritos e discutidos a seguir.

\section{Alguns resultados interessantes sobre o contexto do estudo}

Por meio da análise histórica do fenômeno das favelas na cidade do Rio de Janeiro, nos deparamos com uma realidade complexa, fluida e envolta em ambiguidades e choques de percepções. Entre as facetas dessa história que mais nos chamaram atenção destacamos aqui: (1) a capacidade de resistência dos moradores de favelas; (2) a consolidação da favela com fato social (anos de 1980); (3) a década em que a favela entra na moda (anos de 1990); (4) a preocupação tardia com o levantamento de dados (décadas de 1940 e 1950); (5) a constância da imprensa "desinformadora"; (6) a construção da visão dicotômica entre o morro e o asfalto.

Apesar da vitória das favelas sobre todas as tentativas de extermínio que contra elas foram empreendidas ao longo de um século, na década de 1980 , a idéia de que as favelas eram uma doença social a ser eliminada não cabia mais nos discursos políticos. As favelas não eram mais um episódio, mas fato social consolidado na cidade do Rio de Janeiro 
em alvenaria (Cavalcanti, 2009). Desde então e até os dias de hoje, sua incorporação à cidade formal constitui um desafio ao poder público. Estão as favelas do Rio de Janeiro, com mais de um século de existência, em plena expansão em determinadas áreas da cidade (Cezar, 2002).

Pouco após consolidada, na década de 1990 a favela entra na moda, no entanto, a recente fama que conquista a favela carioca não aparece como um resultado de cem anos de história de luta por sobrevivência, mas da degeneração de valores e violência gerados pelo crime. Tanto no cenário nacional - através da televisão e dos jornais - quanto no cenário internacional - através das telas de cinema -, a violência e a atmosfera de ilegalidade nas favelas passam a ser amplamente divulgadas com fetichismo (Bauman, 2009). Muito provavelmente resultado de uma mídia, sempre presente e (des)informadora aliada a escassez de dados acerca da realidade das favelas e suas dimensōes na cidade. A primeira favela já contava com cinquenta anos de existência quando foi tomada a decisão de realizar um recenseamento específico (Valladares, 2005, p. 62). Os primeiros recenseamentos nas décadas de $1940 \mathrm{e}$ 1950 traziam dados conflitantes e imprecisos sendo corrigidos ao longo das décadas seguintes, com base em novas pesquisas que até hoje ainda são realizadas a fim de diagnosticar a evolução das favelas cariocas. A demora e a insuficiência na geração de dados sobre as favelas aliada à presença massiva de especulações alarmistas da imprensa são a combinação perfeita para a construção de perspectivas fantasiosas e irreais dos espaços urbanos. Acreditamos que este é o caso da percepção da cidade do Rio de Janeiro como uma "cidade partida". Sobre essa crença (Ventura, 1994) questionamos: será que poderíamos tratar a problemática social urbana das favelas do Rio de Janeiro nesses termos dicotômicos? Não é de hoje que as diferentes favelas em diferentes regióes da cidade apresentam realidades plurais e de difícil generalização. A favela carioca, fenômeno que se desenvolve na cidade ao longo de um século, não é realidade uniforme ao longo da cidade (Cavalvanti, 2009). Primeiramente, se observarmos o mapa da cidade do Rio de Janeiro a partir de sua divisão territorial em cinco áreas de planejamento a luz do índice de desenvolvimento social calcula- do pela ONU (Cavallieri e Lopes, 2008), verificamos que as menores taxas de desenvolvimento sociais estão na área de planejamento " 4 " e "5" que corresponde a "Zona Oeste" e "Jacarepaguá" e os melhores, em contrapartida, estão concentrados na Zona Sul da cidade (AP 2). Se observarmos a mapa de Cavallieri e Lopes (2008) quanto ao IDS por bairro, verificamos duas áreas localizadas em meio a Zona Sul da cidade (AP 2) que apresentam IDS diferenciado de todo o restante da região, muito mais baixo. Esses setores representam as favelas da Rocinha e Vidigal. Se analisarmos comparativamente a Zona Oeste (AP 5) e a região que corresponde à área dessas duas grandes favelas na Zona Sul (AP 2) é possível reparar que há melhores taxas de IDS em favelas na Zona Sul da cidade (AP 2) do que na cidade formalmente constituída na Zona Oeste (AP 5). Em termos comerciais, essa realidade se manifesta com a desproporção nos valores de aluguéis. Em 2010, um imóvel formal em Santa Cruz, na Zona Oeste (AP 5) tem um valor médio de aluguel de $\mathrm{R} \$ 200,00$. Em uma favela na Zona Sul (AP 2), este mesmo imóvel pode ter um aluguel de até $\mathrm{R} \$ 700,00$.

No que tange ao crescimento das favelas, essa variação também se manifesta nas diferentes áreas de planejamento municipais. Em dados gerais, em 2000, o crescimento das favelas comparado à cidade formalmente constituída era de seis indivíduos novos na favela para um novo indivíduo na cidade formal (Moreira, 2007). Nesse mesmo período, enquanto a população das favelas da Zona Sul (AP 2) e do Centro (AP 1) decresciam e a das favelas da Zona Norte (AP 3) cresciam modestamente, a população das favelas da Zona Oeste (AP 4 e AP 5) crescia a todo vapor (Moreira, 2011). Os dados mais recentes sobre a expansão das favelas em área, obtidos através de fotografia aérea, mostra que na última década houve uma mudança: enquanto as favelas da Zona Sul (AP 2) decrescem, as favelas do Centro (AP 1) e Zona Norte (AP 3) crescem, as favelas da Zona Oeste (AP 4 e AP 5) vivem um boom.

Os dados sobre a expansão das favelas indicam certa correlação com as taxas de IDS: nas regiōes de menores taxas de IDS, o crescimento das favelas é maior. Além disso, em termos de investimentos públicos, atenção da mídia e das organizações da 
sociedade civil (ONGs), há na cidade do Rio de Janeiro uma concentração de atenções na Zona Sul (AP 2), o cartão-postal da cidade para o Brasil e para o mundo (Moreira, 2011). Conhecer e entender esta dinâmica realidade parece ser o primeiro passo a ser dado para atender efetivamente demandas da coletividade, compor as desarmonias do tecido social e distribuir direitos com equidade.

Mesmo com todas as suas imperfeições, ao longo da história desta cidade, não resta dúvida de que o Estado nunca esteve tão presente nas favelas como nos dias atuais. Favela-Bairro, PAC, UPPs e UPP Social são alguns dos projetos financiados com verba pública que acontecem hoje no intuito de incorporar a favela ao restante da cidade. Saber se esta presença estatal nas favelas se traduz na democratização do acesso aos direitos é nossa questão central. De um lado, a força, de outro, uma enxurrada de projetos sociais que, ainda que mal distribuídos, possivelmente desencadeiam algum efeito sobre as representações de justiça no universo das favelas. Com a continuidade das favelas e seus conflitos sociais em um contexto de medo, falta de confiança e uma escassez de lideranças comunitárias legítimas, dar efetividade aos direitos individuais e coletivos conquistados no bojo da democratização vivida nos anos de 1980 e pôr em prática o rol de direitos fundamentais consagrados pela Constituição Federal de 1988 é o grande desafio a ser enfrentado pelo Poder Público. Seguimos nossa investigação rumo ao Poder Judiciário por meio da análise da atuação do Tribunal de Justiça do Estado do Rio de Janeiro frente a demandas envolvendo as favelas cariocas e seus moradores. Como o Poder Judiciário vem atuando neste cenário é o que analisaremos a seguir.

\section{Alguns resultados interessantes da pesquisa jurisprudencial no TJRJ}

\section{Demandas individuais de moradores de favelas}

Verificamos em nossa análise que a incidência de demandas que discutem a favela ou que foram propostas por moradores de favelas vêm crescendo significativamente ao longo dos últimos anos.
É curioso destacar que, no cenário geral de ações analisados no TJRJ, nos anos de 1980 (entre 1980 e 1989), havia um grupo de demandas (3\%) que já se propunham a discutir a favela, no entanto, como podemos ver na figura 1, nenhuma dessas açōes são propostas por moradores de favelas. Os autores dessas demandas são proprietários de imóveis localizados na cidade formalmente constituída que viram seu patrimônio desvalorizado ou ameaçado em virtude da ocupação irregular de terrenos. Esses proprietários começam, portanto, nos anos de 1980, a se insurgir contra o Estado e a demandar judicialmente não apenas indenizações pelo prejuízo sofrido em seu patrimônio, como também a atuação da administração pública para a remoção destas favelas. Nos anos de 1980, portanto, todas as ações estudadas foram propostas em face do Estado.

Com o passar do tempo, o perfil do autor dessas ações começa a mudar. Os anos de 1990 vai contar com um crescente número de demandantes moradores de favelas ${ }^{14}$. Este número torna-se ainda mais significativo nos últimos dez anos.

Figura 1 - Variação do $\mathrm{n}^{0}$ de ações registradas no TJRJ relacionadas objetiva ou subjetivamente com a favela

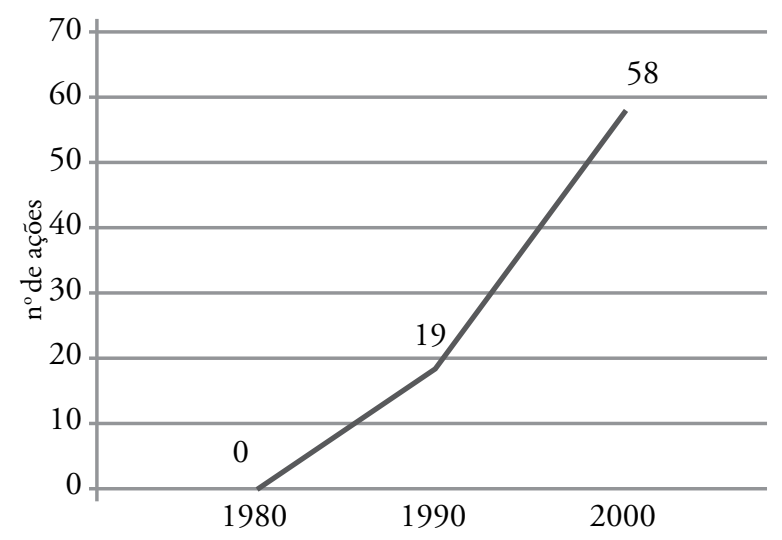

Esta ilustração é composta um gráficos da pesquisa de Moreira (2011). O gráfico em linha, extrai a partir do cenário geral de demandas que discutem a favela, apenas as demandas propostas por moradores de favelas, apresentando o número de demandas encontradas para esses mesmos períodos. 


\section{Demandas judiciais coletivas relacionadas com as favelas cariocas}

As demandas coletivas seriam as ações civis públicas e coletivas, propostas pelo rol de atores definidos em lei ${ }^{15}$ com a finalidade também definida em lei ${ }^{16}$ de defender interesses difusos, coletivos $\mathrm{e}$ individuais homogênios da coletividade. Investigando nos deparamos, portanto, com o seguinte cenário entre 1980 e 2009: enquanto 97\% das ações eram demandas individuais, $3 \%$ eram ações civis públicas.

Apenas 3\% das demandas, ao longo de três décadas, possuem abrangência coletiva. Este universo (3\%) - constituído de ações civis públicas - está concentrado nos anos de 1990 (de 1990 a 1999). Não encontramos nenhum registro de ações desta natureza seja nos anos de 1980 (de 1980 a 1989), ou recentemente (de 2000 a 2009). Este cenário nos faz questionar que motivos estariam gerando tal fenômeno? Será que as comunidades faveladas do Rio de Janeiro não possuem demandas coletivas ou existe algum obstáculo que impeça a propositura e/ou trâmite deste tipo de ação no Judiciário? $\mathrm{Na}$ tentativa de entender o fenômeno, conversamos com alguns advogados que atuam em instituições ligadas à Renap (Rede de Advogados Populares $)^{19}$. A realidade narrada aponta para o fato de que os grupos sociais desprivilegiados economicamente não são protagonistas de açôes judiciais de natureza coletiva. Na maioria dos casos, estes grupos figuram como réus e procuram o auxílio de advogados populares para promover sua defesa. Por outro lado, também esteve presente em todas as narrativas o fato de que muitas demandas de natureza coletiva são suspensas em primeira instância em razão da - nas palavras dos entrevistados - "timidez dos juízes em proferir decisōes deste tipo", ou seja, decisóes de caráter administrativo que possam afetar o princípio da separação de poderes e gerar políticas públicas, especialmente em questões polêmicas com muitos interesses em jogo. Estas informaçōes, que não são novidade e foram registradas por outros estudiosos do tema (Falcão, 1989; Junqueira, 1996), possivelmente apontam para os reais motivos da última década não apresentar nenhum registro de Açóes Coletivas que versem so- bre a favela carioca ou proposta por iniciativa de seus moradores no TJRJ.

\section{Tempo de duração dos litígios, apenas uma curiosidade}

Para investigar o tempo de duração dos julgados estudados descartamos do nosso n. amostral todos os recursos interlocutórios: Agravos de Instrumento e os Embargos à Execução. Todos os demais recursos interpostos perante o TJRJ - Apelaçôes e Embargos infringentes -, bem como ações de competência originária do TJRJ - Mandado de Segurança e Habeas Corpus - e seus respectivos anos de julgamento foram considerados na composição desse espaço amostral pensado exclusivamente para cálculo do tempo médio de duração dessas demandas judiciais perante o TJRJ. Com base nesses critérios, apuramos o seguinte tempo de duração dos processos entre 1980 e 2009.

Verificamos que, no quadro geral, as ações com demandas relacionadas às favelas cariocas apresentam, no período estudado, dois picos bem definidos: $1^{\circ}$ ) ações que duram de um a dois anos e; $2^{\circ}$ ) açóes que duram entre 3 e 4 anos. Este fenômeno parece ser melhor esclarecido quando analisamos separadamente as açóes propostas por moradores de favelas e as ações propostas por pessoas que não moram na favela. Conforme vemos, entre as pessoas que não moram em favela a maioria das açôes propostas têm um tempo médio de duração de 1 ano, influenciando diretamente o pico de um ano que se verifica na linha de tendência geral. Já quando analisamos o tempo de duração das ações propostas por moradores de favelas, este cenário muda e o pico com o maior número de ações está no período de 3 a 4 anos, influenciando diretamente o segundo pico que se verifica também na linha em azul. Em outras palavras, enquanto as açôes propostas por moradores de favelas tendem a demorar mais, entre 3 e 4 anos, as demandas dos demais moradores da cidade formal, com perfil de proprietários de imóveis, dura em média 1 ano. Este fenômeno pode estar relacionado ao fato de que moradores de favelas, em geral, não possuem recursos para custear advogados particulares. $\mathrm{Na}$ maioria das vezes, os moradores de favelas são 


\section{Figura 2 - Tempo de Duração das Açóes}

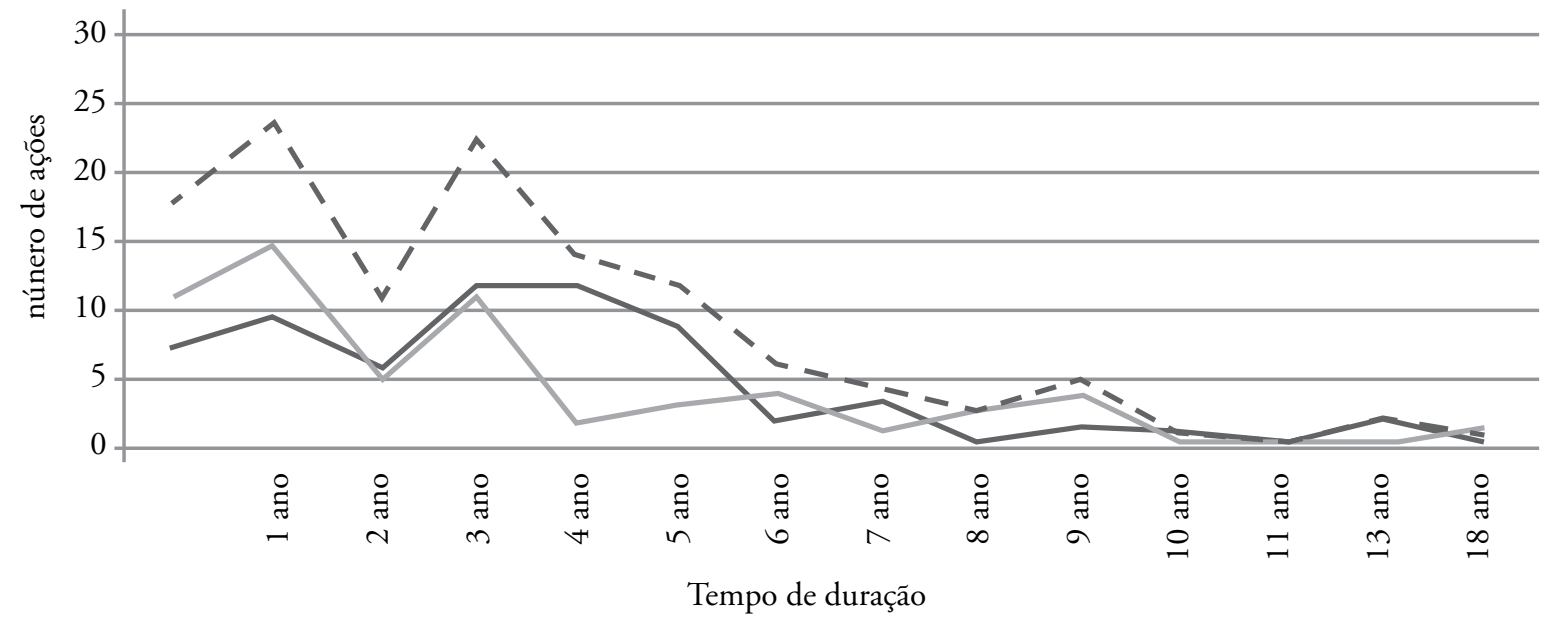

- - Panorama geral do recorte amostral Panorama para demais demandantes

atendidos por advogados voluntários de projetos sociais ou defensores públicos. A desproporção entre a quantidade de denfensores disponíveis e a parcela de população que assistem ${ }^{18}$ pode ser uma possível causa da diferença entre o tempo de duração das demandas propostas por moradores de favelas quando comparadas ao tempo de duração das demandas propostas por proprietários de imóveis que não residem em favelas.

O perfil das demandas ao longo dos anos: o que os moradores de favelas esperam dos tribunais?

Ao longo dos anos, o que se verifica é uma ampliação não apenas quantitativa no número de demandas propostas por moradores de favelas (Figura 3), mas também, um salto qualitativo no conteúdo dessas demandas.

Enquanto nos anos de 1980 (entre 1980 e 1989) não há qualquer demanda proposta por moradores de favelas no acervo jurisprudencial do TJRJ (ver Figura1). Nos anos de 1990 (entre 1990 e 1999) essas demandas começam a aparecer primordialmente em face do Estado em razão de ameaças à vida e à integridade física desses moradores tanto por obras do projeto favela-bairro quanto por balas perdidas em confrontos entre traficantes e po-
Panorama para moradores de favelas

liciais. Nos últimos dez anos (entre 2000 e 2009) o que se verifica além do aumento de demandas de moradores de favelas, é o incremento no rol de demandados por moradores de favelas. O morador de favela agora, além de buscar o Judiciário para proteger sua vida e integridade física, aparece como consumidor insatisfeito com a má prestação de serviços em relaçôes de consumo de serviços de telefonia, TV a cabo, luz, gás, entre outros. Nos últimos anos também desperta a curiosidade o fato de aparecerem demandas de moradores de favela frente a outros moradores de favela. Este tipo de situação há alguns anos não seria imaginada uma vez que as questôes entre moradores de favelas tradicionalmente são resolvidas no âmbito da própria comunidade (Strozenberg, 2001; Santos, 1988; Santos 1989a; Moreira, 2006; Moreira, 2007).

E os juizes, como vêm se posicionando frente a essas demandas?

Ao longo dos anos de 1980, as demandas relacionadas com as favelas eram escassas no Tribunal de Justiça (TJRJ) e as poucas demandas que havia eram propostas por cidadãos que não moravam na favela. Esses proprietários de imóveis na cidade formalmente constituída estavam sofrendo prejuízos 
em seu patrimônio com a desvalorização gerada pela presença de favelas nas redondezas. Algumas dessas ações tinham como pedido uma reparação pecuniária, outras, no entanto, pediam a remoção das favelas. Nessa época, anos de 1980, a postura dos desembargadores do TJRJ foi de evitar tomar decisões. O Tribunal sabia que decisões desse nível interfeririam diretamente na gestão municipal. Uma ordem judicial à administração pública para remover favelas consubstanciaria uma decisão de natureza político-administrativa, característica do poder Executivo. Nos anos de 1980, portanto, os magistrados do TJRJ preferem não interferir.

Nos anos de 1990, o cenário das comunidades faveladas mudou novamente, infelizmente para pior. Diante da falta de recursos e da violência que ganha força com o tráfico de drogas cada vez mais armado, as organizações comunitárias tornam-se frágeis e fragmentadas. Muitos conflitos, que antes eram encaminhados para resolução na sede de organizações comunitárias (Santos, 1988; Moreira, 2006), passaram a contar cada vez menos com espaços públicos comunitários legitimados para tal. As lideranças encarregadas dos encaminhamentos de conflitos dentro das comunidades faveladas tornaram-se cada vez mais escassas, expulsas, assassinadas ou corrompidas na guerra contra (e pelo) tráfico de drogas. É nesta época, meados dos anos de 1990 , que se observa o início da propositura de demandas judiciais por moradores de favelas no Tribunal. Essas primeiras demandas estavam relacionadas com acidentes com projetos de urbanização e balas perdidas na guerra entre policiais e traficantes.

O número de demandas relacionadas com as favelas cariocas ao longo dos anos de 1990 aumenta e os magistrados do TJRJ mudam de postura. O Tribunal passa a se posicionar sobre as questôes sociais e políticas das favelas. Ao longo dos anos de 1990, portanto, o TJRJ começa a tomar decisóes em casos polêmicos que demandam um posicionamento político em relação à atuação da administração pública. Como "água mole em pedra dura, tanto bate até que fura", o TJRJ finalmente começa a declarar entendimentos políticos sobre as favelas. Nos anos de 1990, os juízes do TJRJ expuseram suas opinióes políticas, bem como realizaram análises de contexto social em demandas relacionadas às favelas. Foi identificada, ainda nesse período, certa dose de decisões criativas, nas quais os juízes de maneira ativa inovaram em relação ao ordenamento jurídico vigente, extrapolando o dispositivo da lei em busca de uma decisão social ou politicamente eficaz. Nesse sentido, o ativismo judicial ${ }^{19}$ encontrado em algumas decisōes judiciais ao longo dos anos de 1990 expressa a postura proativa do julgador a fim de interpretar expansivamente a Constituição, para além das limitações da legislação infraconstitucional, potencializando o sentido e alcance das normas constitucionais. (Barroso, 2008).

Antes de chegarmos a qualquer conclusão sobre essa mudança de postura do Tribunal é preciso conhecer esse posicionamento político e checar sua coerência em relação à realidade social sobre a qual se projeta. Em pequena parte dos julgados estudados ao longo dos anos de 1990 (6\%), o entendimento do Tribunal era o de que a administração pública era omissa e não cumpria com sua função ao não evitar ocupações irregulares. Nesse sentido, adotava o seguinte posicionamento político: as favelas devem ser removidas. Ora, para que as decisões judiciais sejam eficientes e politicamente viáveis, seu conteúdo precisa ter os dois pés na realidade social. Caso contrário, o conflito entre as decisões judiciais e a falta de viabilidade de sua execução gera apenas ineficácia e perda de confiança nas instituições judiciais. Assim, nos anos de 1990, decisões que determinam a remoção de favelas consolidadas estavam nitidamente na contramão da história. As favelas, nessa época, já eram fato social consolidado e todas as políticas públicas empreendidas eram com o intuito de urbanização e promoção de dignidade nesses espaços. Apesar desse tipo de decisão, ainda nos anos de 1990, em muitos outros julgados o TJRJ andou bem. Houve casos onde juízes subiram as favelas para fazer inspeção local em conflitos entre vizinhos e muitos outros onde os juízes consideraram valores sociais e culturais locais para balizar suas decisões em demandas propostas por moradores de favelas (Moreira 2011).

Recentemente - entre 2000 e 2009 -, as demandas propostas por moradores de favelas se multiplicaram. Demandas semelhantes às propostas nas duas décadas anteriores - com pedidos de remoção de favelas - se misturaram no Tribunal a 
Figura 3 - Análise Comparativa do $\mathrm{N}^{\circ}$ de Demandas por AP ao Longo de 190 e 2009 - Considerando Busca de Jurisprudênciado Tirja Partir do Nome das Três Maiores Favelas em $\mathrm{Km}^{2}$ em Cada AP

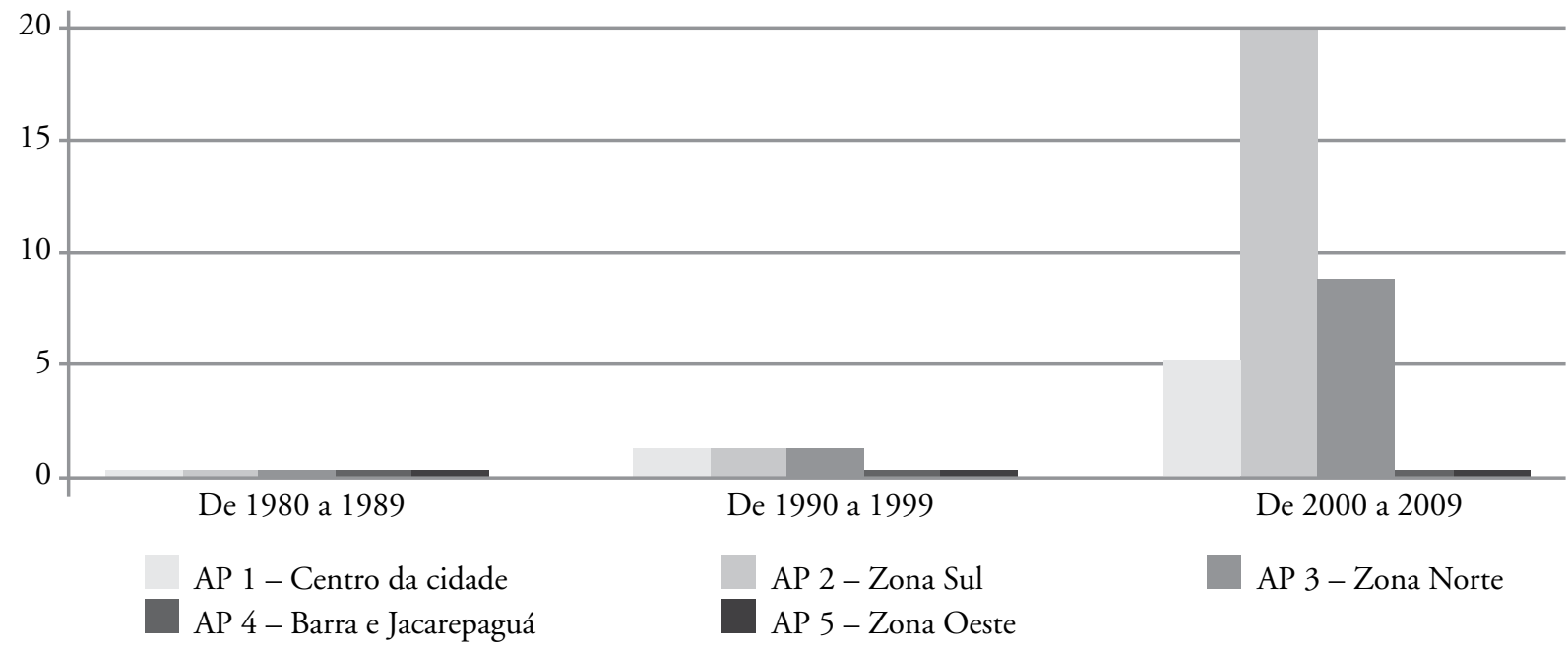

Figura 3. Análise comparativa do número da incidência no TJRJ de demandas cíveis ao longo do tempo - de 1980 a 2009 - relacionadas com as três maiores comunidades $\left(\mathrm{em} \mathrm{m}^{2}\right)$ em 2008, segundo o sistema Sabren, ou a seus moradores, a partir de pesquisa com o nome dessas favelas como chave de busca no acervo jurisprudencial do Tribunal.

um volume muito maior de demandas que levavam para os magistrados a ótica do morador dessas comunidades. Nesse período, parece também que o Tribunal ajustou suas lentes e afinou seu entendimento com a temporalidade das favelas na realidade da cidade. É possível ver mais coerência entre as decisões judiciais e a realidade social. $\mathrm{Na}$ medida em que as ações relacionadas objetiva e subjetivamente às favelas se multiplicam, o TJRJ parece ter se familiarizado cada vez mais com essa realidade social e seus conflitos ${ }^{20}$. Se nos anos de 1980 a postura no TJRJ era a de evitar decisões que interferissem politicamente na gestão da administração pública e nos anos de 1990 essa postura é substituída pela adoção de um posicionamento ativo, mas inicialmente descontextualizado historicamente com a realidade social das favelas, nessa última década o TJRJ parece reajustar o prumo em busca de decisões mais afinadas com a realidade, em um lugar entre a estagnação e o ativismo. Isso pode ser visto principalmente através da análise dos argumentos políticos, sociais e jurídicos nos quais os magistrados pautaram suas decisões ao longo das três últimas décadas (Moreira, 2011).
$O$ acesso dos moradores de favelas ao Judiciário nos diferentes espaços urbanos: uma questão de desenvolvimento social?

No que tange ao volume de demandas ao longo dos últimos trinta anos, o cenário foi bastante diversificado, não apenas no tempo, mas também nas diferentes áreas de planejamento do município do Rio de Janeiro.

A Figura 3 nos mostra que nos anos de 1980 não há incidência de qualquer demanda relacionada com essas comunidades no TJRJ. Portanto, nenhuma novidade em relação ao que já foi visto (Figura 1). Nos anos de 1990, no entanto, começamos a ver algumas demandas nas áreas de planejamento AP 1 (Centro), AP 2 (Zona Sul) e AP 3 (Zona Norte). Essas demandas não ocorrem de maneira uniforme em todas as áreas de planejamento do município. As favelas da região que abrange a Barra da Tijuca e Jacarepaguá (AP 4), bem como as favelas do restante da Zona Oeste carioca (AP 5), não apresentam qualquer registro de demanda durante os anos de 1990 em nosso espaço amostral. Nos últimos dez anos (entre 2000 e 2009) este qua- 
dro sofre novas mudanças. As demandas propostas por favelas da Zona Sul carioca (AP 2) disparam em um crescimento consideravelmente maior que o apresentado pelas demais regiões. A Zona Norte (AP 3) aparece em segundo lugar no ranking de demandas relacionadas às suas favelas, seguida da Zona Central da cidade (AP 1), cujo crescimento se nota de maneira mais contida ${ }^{21}$. Há, portanto, um crescimento assimétrico na busca dos moradores de favelas pelo Judiciário entre as diferentes áreas de planejamento municipais do Rio de Janeiro. Como explicar essa assimetria?

Além de pensar nos diferentes índices de desenvolvimento sociais (Cavallieri e Lopes, 2008), outra possibilidade que nos ocorreu seria uma descentralização do Tribunal de Justiça na direção da Zona Sul (AP 2), o que poderia facilitar o acesso dos moradores das favelas dessa região ao TJRJ. Na busca de eficiência na tarefa de distribuir justiça e para facilitar o acesso do cidadão ao Judiciário, o Tribunal de Justiça do Estado do Rio de Janeiro, com sede no Cento da cidade (AP 1), desconcentrou suas atividades, distribuindo-se ao longo da cidade através de foros regionais ${ }^{22}$.

A finalidade dos foros regionais ${ }^{23}$ é levar o Judiciário para mais perto do jurisdicionado nas diferentes áreas da cidade, ainda que bastante afastadas da AP 1, onde se localiza o foro central, facilitando assim o acesso da população à justiça através do Judiciário estatal. (Organização, 2008).

Ocorre que, o Tribunal de Justiça do Estado do Rio de Janeiro não disponibiliza foros regionais na Zona Sul, que é atendida pelo Foro central. Como entender o fato de que, ainda assim, as favelas da Zona Sul carioca têm apresentando, de acordo com os dados dessa pesquisa, uma facilidade maior em acessar direitos pela via judicial?

Podemos pensar em um primeiro momento que esses foros regionais constituem verdadeira novidade na realidade da cidade do Rio de Janeiro quando comparados ao foro central e, possivelmente, ainda estariam sendo assimilados pela população, que muitas vezes tem no foro central a referência de Judiciário estatal. Este fato pode nos ajudar a explicar o fato de que, apesar de existirem muitos foros regionais na Zona Oeste da cidade do Rio de Janeiro, não se verificam demandas relacionadas às favelas desta região no TJRJ.
Esta realidade parece apontar ainda para o fato de que variáveis, como os índices de desenvolvimento social, investimento público na promoção de infraestrutura e serviços básicos, a presença da sociedade civil organizada e a pacificação de favelas, podem influenciar a dinâmica do acesso de moradores de favelas à justiça de maneira mais direta que a descentralização geográfica do Tribunal de Justiça.

\section{Consideraçôes finais}

As variáveis da democratização do acesso ao Judiciário para moradores de favelas da cidade do Rio de Janeiro no tempo e no espaço foram objeto de uma investigação que levou em consideração aspectos do acesso individual e coletivo, bem como do posicionamento de magistrados do Tribunal de Justiça em suas decisões. De um lado o acesso das favelas ao Judiciário no tempo e no espaço, de outro a resposta dos magistrados do TJRJ. Dentre os muitos dados e análises trazidos à superfície ao longo desse estudo, alguns pontos nos chamaram especial atenção: (1) relação entre o volume de demandas individuais e os índices de desenvolvimento sociais; (2) frequência das demandas coletivas, das altas expectativas constituintes ao vazio na realidade nos tribunais; (3) coerência entre as posiçôes assumidas pelo TJRJ frente às favelas e seus moradores e a realidade social e seus ajustes ao longo do tempo.

Desde os anos de 1980 e, mais fortemente, na última década analisada nesse trabalho (de 2000 a 2009), o Estado esteve presente nas comunidades faveladas como nunca antes na história. Apesar dessa presença não ser uniforme, é possível reparar seus efeitos sob as favelas beneficiadas com projetos e investimentos públicos. Desde então, o poder Judiciário vem sendo cada vez mais demandado a determinar que o Estado cumpra com suas obrigações, através de uma administração pública eficiente e capaz de distribuir direitos com respeito à vida e à integridade física do cidadão e com serviços públicos essenciais prestados com respeito ao consumidor. Tudo isto é inédito e revela em nosso cenário urbano transformações reais para a democratização da sociedade e do Estado. Apesar das dificuldades, 
os moradores de comunidades faveladas vêm procurando cada vez mais o Judiciário para resolução de conflitos com vizinhos e familiares. Nesse contexto é grande a responsabilidade do Judiciário como poder do Estado e esfera pública capaz de mediar expectativas entre cidadãos e administração pública. Consideramos a jurisdição uma das vias de agitação permanente da cidadania. Assim, a eficiência da atuação jurisdicional do Estado é uma contribuição central na democratização da nossa sociedade. Cada vez mais o Judiciário vem assumindo seu papel no cenário político, no entanto, como vimos, esse movimento precisa estar afinado com as transformações sociais, políticas, econômicas e culturais que acontecem da porta para fora do Tribunal de Justiça.

\section{Notas}

1 A prefeitura da cidade do Rio de Janeiro divide o município em cinco áreas de planejamento (APs): AP 1 - Centro; AP 2 - Zona Sul; AP 3 - Barra da Tijuca e Jacarepaguá; AP 4 - Zona Norte; AP 5 - Zona Oeste. É esta a divisão territorial que utilizamos para levantamento de dados, análise e comparação.

2 As fontes dos parâmetros utilizadas na análise estão indicadas em Moreira (2011).

3 No âmbito da justiça civil, muito mais do que na justiça penal, é possível falar em procura real ou potencial à justiça (Santos, 1989). Apesar de haver um número ainda maior de julgados no âmbito da justiça penal com a palavra "favela", na maioria desses casos o morador de favela figura na qualidade de réu (Lopes, 1989; Santos, 1989).

4 A palavra "favela" foi escolhida em detrimento da palavra "comunidade", pois esta última trazia inúmeros outros julgados relacionados às mais diversas comunidades, dentre eles, poucos julgados relacionados às comunidades faveladas. Para melhor atender aos propósitos desta pesquisa optamos pela palavra de busca "favela" para levantamento de julgados do TJRJ.

5 "A primeira atua em níveis da realidade, onde os dados se apresentam aos sentidos [...]. A segunda trabalha com valores, crenças, representações, hábitos, atitudes e opiniōes. A primeira tem como [...] objetivos trazer à luz dados, indicadores e tendências observáveis [...]. A segunda, [...] aprofundar a complexidade de fenômenos, fatos e processos particulares e específicos de grupos [...].” (Minayo e Sanches, 1993, p.05).
6 Vale destacar que as informações levantadas nesta análise não são objetivas e incontroversas como as elencadas na análise quantitativa dos cabeçalhos dos julgados, mas fruto de interpretação das pesquisadoras acerca dos conteúdos das ementas de decisões judiciais.

7 Não foi possível acessar ao nome da ação em sede de primeira instância para cada um dos recursos analisados em nosso recorte amostral. Esta informação foi estimada com base na interpretação do conteúdo das ementas dos julgados do TJRJ ora analisados e não por dados fornecidos pelo próprio TJRJ.

8 A ação judicial que tem como objeto jurídico uma relação contratual, no mundo real pode visar a prestação de serviço público essencial como luz ou água. Para identificar o interesse das demandas no mundo real criamos a categoria analítica "objeto material".

9 Nosso espaço amostral é constituído por julgados que foram levantados em pesquisa no site do TJRJ no ano de 2010. Este espaço amostral pode, portanto, sofrer mudanças a curto e longo prazo na medida em que recursos interpostos perante o TJRJ ao longo destas últimas três décadas forem julgados após a data deste levantamento.

10 O levantamento foi feito com base nas informaçōes disponibilizadas pelo banco de dados "Cadastramento de Assentamentos Urbanos de Baixa Renda", intitulado "Sabren" (Sistema de Assentamentos de Baixa Renda). Este sistema é o que há de mais completo e atualizado sobre as favelas cariocas.

11 As informações sobre o crescimento vegetativo da população das favelas teve sua última atualização em 2000, ano do último senso do IBGE publicado até esta data. A área destas comunidades e sua expansão foram atualizadas no sistema Sabren com base em fotografias de satélites até 2008, dado mais recente disponível.

12 Conforme escrito no sistema Sabren.

13 A única diferença nesse levantamento foi a palavra-chave de busca utilizada para pesquisa dos julgados. Aqui, utilizamos o nome de cada uma das comunidades selecionadas para estudo (tabela 1; tabela 2; tabela 3; tabela 4; tabela 5). Os julgados levantados também foram triados. Mais detalhes em Moreira (2011).

14 A primeira ação proposta por um morador de favela que encontramos data de 1993. Trata-se de demanda proposta por morador de favela em face de outro também morador de favela, um ex-marido e uma ex-mulher que em seu divórcio discutiam sobre o valor do imóvel que ambos construíram juntos na favela onde moravam. Como 
a grande maioria dos imóveis construídos em favela, este imóvel era uma construção irregular e no "bom direito" não possuía valor comercial. $\mathrm{O}$ juiz que julgou a demanda na primeira instância, em respeito ao direito positivo e à "ordem pública”, não falou sobre a partilha do imóvel, considerando o mesmo sem valor econômico e, portanto, juridicamente inexistente no mundo formal. A demanda supreendentemente chega ao Tribunal de Justiça e o mesmo se posiciona à altura da provocação: entende que o imóvel na favela possui sim valor econômico e determina que o juiz em primeira instância proceda a partilha do bem. Apesar da inovação que o caso traz ao mundo jurídico, é relevante ponderar que entendimentos diversos foram manifestados por outros desembargadores do TJRJ em casos semelhantes ao longo das três décadas analisadas. Um exemplo disso é o julgado proferido em 2008 pela Sétima Câmara Cível, onde a desembargadora Maria Henriqueta Lobo adere ao entendimento de que o imóvel em favela não possui valor comercial em sua decisão. Trata-se do Julgado proferido em 04 de junho de $2008 \mathrm{em}$ sede de Agravo de Instrumento. Processo $\mathrm{n}^{\circ}$. 0015054-26.2008.8.19.0000 (2008.002.06554), com a seguinte ementa: "Agravo de instrumento. Execução de título judicial. Penhora de bem imóvel. Pedido de substituição do bem penhorado. Indeferimento. Não anuência do credor. Bem imóvel oferecido pelo executado em substituição que se encontra encravado dentro de uma favela, não possuindo qualquer valor no mercado imobiliário. É lícito ao credor recusar bens oferecidos à penhora que se revelarem de difícil alienação, isto porque a execução é feita no seu interesse, e não no do devedor. Inexistência, ainda, de prova nos autos do registro imobiliário competente do imóvel oferecido pelo executado. Desprovimento do recurso." (nosso grifo).

15 Art $5^{\circ}$ da lei 11.448/07.

16 Art. $1^{\circ}$ da Lei 7.347/85.

17 Esta rede é formada de instituições especializadas em demandas coletivas envolvendo conflitos rurais de terras tendo ampliado nos últimos anos sua prática para abarcar cenários urbanos com um viés coletivo. $\mathrm{Na}$ cidade do Rio de Janeiro, o Centro ligado à Renap, "Mariana Criola", foi fundado em 2007.

18 Segundo dados do CN J, em 2006 a população brasileira contava com 1,48 defensores públicos para cada 100.000 habitantes (Anadep, 2008). Na cidade do Rio de Janeiro, no ano de 2008, para 6.161.047 habitantes havia 634 defensores (Anadep, 2008), um defensor público para cada $9.717,73$ habitantes.

19 O termo ativismo judicial aqui é entendido diferente de "judicialização" da política (Barroso, 2008). A discussão sobre ativismo judicial e judicialização da política é ampla. Para conhecer mais dessa discussão ver Vianna, 1999; Barroso, 2008; Cittadino, 2004.

20 As decisões judiciais, desde meados dos anos de 1990 até o final desta última década, revelam o maior conhecimento de magistrados em relação às favelas cariocas. Para mais comentários acerca da evolução dos julgados do TJRJ neste sentido vide Moreira, 2011.

21 Nota-se que a evolução do número de demandas que se verifica ao longo dos últimos dez anos nos diferentes espaços urbanos parece coerente com o quadro geral de demandas relacionadas às favelas cariocas ao longo do tempo, com destaque para o seu recente boom.

22 Não consideramos nesta análise os Juizados Especiais uma vez que os julgados estudados são parte do acervo jurisprudencial cível do TJRJ, não proveniente de ações que tramitaram em Juizados Especiais.

23 O poder Judiciário do Estado do Rio de Janeiro é regulado em sua administração e funcionamento pelo Código de Organização e Divisão Judiciária do Estado do Rio de Janeiro, o CODJERJ. Na cidade do Rio de Janeiro temos a chamada Comarca da Capital, composta pelo foro central e dez foros regionais distribuídos pela cidade conforme o gráfico da figura 8 .

\section{BIBLIOGRAFIA}

ABRAMO, Pedro. (2003), "A dinâmica do mercado de solo informal em favelas e a mobilidade dos pobres." Disponível em <http://www. armazemdedados.rio.rj.br/arquivos/105a $\% 20$ dinâmica $\% 20$ do $\% 20$ mercado $\% 20$ de $\% 20$ solo\%20informal\%20em\%20favelas.PDF>. Acesso em 6 abr. 2009.

ANADEP. (2008), "Amazonas, Ceará, Mato Grosso, Minas Gerais e Rio de Janeiro - Defensores públicos comemoram dia nacional orientando a população." Jornal da Associação Nacional dos Defensores Públicos. Disponível em < http://www.anadep.org.br/wtk/pagina/ materia?id=3636> . Acesso em 10 jan. 2011.

BARROSO, Luís Roberto. (2008), "Judicialização, ativismo judicial e legitimidade democrática". Disponível em <http:// www.oab.org.br/oabeditora/users/revista/1235066670174218181901.pdf>. Acesso em 23 jul 2009. 
BAUMAN, Zydmunt. (2009), "Entrevista especial com Zidmunt Bauman: ecologia humana”. Disponível em <http://www.portaldomeioambiente.org.br/ecologia-humana/2142-entrevista-especial-zygmunt-bauman-primeira-parte. html>. Acesso em 17 out. 2010.

BESSERMAN, Sérgio. CAVALLIERI, Fernando. (2004), "Nota técnica sobre o crescimento da população favelada entre 1991 e 2000 na cidade do Rio de Janeiro". Coleção Estudos Cariocas. Instituto Pereira Passos, Prefeitura da Cidade do Rio de Janeiro, n. 20040601: 1-7.

BURGOS, Marcelo Baumann. (1999), "Dos parques proletários ao favela-bairro”, in Z., Alba e M. Alvito (orgs.), Um século de favela, Rio de Janeiro, FGV.

CAMPILONGO, Celso Fernandes. (1989), "Magistratura, sistema jurídico e sistema político”, in J. E. Faria (org.), Direito e justiça, a função social do judiciário, São Paulo, Ática.

CASTRO JUNIOR, Osvaldo Agripino de. (2007), $A$ democratização do poder Judiciário. Porto Alegre, Fabris.

CAVALCANTI, Mariana. (2009). "Do barraco a casa: tempo, espaço e valor(es) em uma favela consolidada". Revista Brasileira de Ciências Sociais, 24 (69): 69-80.

CAVALLIERI, Fernando. LOPES, Gustavo Peres. (2006), "Favelas cariocas: comparação das áreas ocupadas 1999-2004”. Coleção Estudos Cariocas. Instituto Pereira Passos, Prefeitura da Cidade do Rio de Janeiro, n. 20061201:49.

. (2008), "Índice de Desenvolvimento

Social (IDS): comparando as realidades microurbanas da cidade do Rio de Janeiro". Coleção Estudos Cariocas. Instituto Pereira Passos, Prefeitura da Cidade do Rio de Janeiro, n. 20080401: 1-12.

CEZAR, Paulo Bastos. (2002), "Evolução da população de favelas na cidade do Rio de Janeiro: uma reflexão sobre os dados mais recentes". Coleção Estudos Cariocas. Instituto Pereira Passos, Prefeitura da Cidade do Rio de Janeiro, $n$. 20020201: 1-13.

CITTADINO, Gisele. (2000), Pluralismo, direito e justiça distributiva: elementos da filosofia consti- tucional contemporânea. 2. ed., Rio de Janeiro, Lumen Juris.

(2002), "Judicialização da política, constitucionalismo democrático e separação de poderes", in W. Vianna (org.), A democracia e os três poderes no Brasil. Belo Horizonte, Editora UFMG.

(2004), "Poder Judiciário, ativismo judicial e democracia”. Revista ALCEU, 8 (09): 105-112.

FALCÃO, Joaquim de Arruda. LOPES, José Reinaldo de Lima. (1989), "Democratização e serviços legais", in J. E. Faria (org.), Direito e justiça, a função social do judiciário. São Paulo, Ática.

FARIA, José Eduardo. (1989a), "Apresentação", in J. E. Faria (org.), Direito e justiça, a função social do Judiciário. São Paulo, Ática.

(1989b), "O modelo liberal de direito e Estado. Direito e Justiça, a função do Judiciário", in J. E. Faria (org.), Direito e justiça, a função social do Judiciário. São Paulo, Ática.

(1989c), "Ordem legal x mudança social: a crise do Judiciário e a formação do magistrado", in J. E. Faria (org.), Direito e justiça, a função social do Judiciário. São Paulo, Ática.

. (2003), "Direito e justiça no século

XXI: a crise da Justiça no Brasil." Anais do Congresso International Conference on Law in the 21st Century, Coimbra, 29: 31-39.

FARIA, José Eduardo; LOPES, José Reinaldo de Lima. (1989), "Pela democratização do Judiciário", in J. E. Faria (org.), Direito e justiça, a função social do Judiciário. São Paulo, Ática.

JUNQUEIRA, Eliane Botelho. (1996), “Acesso à justiça: um olhar retrospectivo”. Revista Estudos Históricos, 18: 389-402.

JUNQUEIRA, Eliane Botelho; VIEIRA, José Ribas \& FONSECA, Maria Guadalupe Piragibe da. (1997), Juizes: retrato em preto e branco. Rio de Janeiro, Letra Capital.

KATO, Shelma Lombardi de. (1989), "A crise do direito e o compromisso da libertação", in J. E. Faria (org.), Direito e justiça, a função social do Judiciário. São Paulo, Ática.

MINAYO, Maria Cecília de S. \& SANCHES, Odécio. (1993), "Quantitativo-qualitativo: 
oposição ou complementaridade?". Revista Caderno de Saúde Pública, Rio de Janeiro, 9(3): 239-262.

MOREIRA, Rafaela Selem. (2006), Efetivação de direitos: limites e possibilidades no contexto de uma favela carioca. Pontifícia Universidade Católica, Rio de Janeiro. Departamento de Direito. Monografia de conclusão de curso.

. (2007), "Mediação de conflitos: limites e possibilidades no contexto de uma favela carioca”. Revista Direito, Estado e Sociedade, 30: 212-229

(2011), Democratização do Judiciário na cidade do Rio de Janeiro: Um Estudo sobre o acesso individual e coletivo de moradores de favelas à Justiça contextualizado à luz de uma história de desigualdades. Dissertação de mestrado. Pontifícia Universidade Católica, Rio de Janeiro. Departamento de Direito.

NERI, Marcelo Côrtes. (2010), "Desigualdade e favelas cariocas: a cidade partida está se integrando?", in M. C. Neri. (org.), Rio de Janeiro, FGV, CPS. - Centro de Políticas Sociais Fundação Getúlio Vargas.

OBSERVATÓRIO DE FAVELAS. (2009), "Muro nas favelas". Disponível em <http://www. observatoriodefavelas.org.br/observatoriodefavelas/noticias/mostraNoticia.php?id_content $=517>$. Acesso em 10 nov. 2010.

ORGANIZAÇÃO judiciária do Tribunal de Justiça do Estado do Rio de Janeiro e o funcionamento das Varas de Família do Fórum Central. (2008). Departamento de Direito. Monografia de pós-graduação.

PANDOLFI, Dulce Chaves; GRYSZPAN, Mario. (2003), A favela fala: depoimentos ao CPDOC. Rio de Janeiro, FGV.

PEREIRA, Luiz Carlos Bresser \& GRAU, Nuria Cunill. (1999), "Entre o estado e o mercado: o público não estatal", in L.C. B. Pereira \& N. C. Grau (orgs.), O público não estatal e a reforma do Estado. Rio de Janeiro, FGV.

PERLMAN, Janice. (2003), "Marginalidade: do mito à realidade nas favelas do Rio de Janeiro". Coleção Rio Estudos. Instituto Pereira Passos, 102: 1-19.

PILATTI, Adriano. (2008), A Constituinte de
1987-1988: progressistas, conservadores, ordem econômica e regras do jogo. 1. ed. Rio de Janeiro, Lumen Juris - PUC-Rio.

PINHEIRO, Ybelmar Chouin. (1940), "O que eu vi na Favella”. Coleção Estudos da Cidade. Rio Estudos. Instituto Pereira Passos, 140: 1-52.

RIO ESTUDOS. Favelas 2004. Disponível em <http://www.armazémdeda dos.tio.gov.br/ arquivos/1378_favelas\%20-\%202004.JPG>. Acesso em 06 abr. 2009.

RIO ESTUDOS. Favelas 2008. Disponível em <http://www.armazémdeda dos.tio.gov.br/ arquivos/1378_favelas\%20-\%202008.JPG>. Acesso em 06 abr. 2010.

ROCHA, Marisa Lopes da \& AGUIAR, Kátia Faria de. (2003), "Pesquisa-intervenção e a produção de novas análises". Revista Psicologia Ciência e Profissão, 23 (4): 64-73.

RUIVO, Fernando. (1989), "Aparelho judicial, estado e legitimação", in J. E. Faria (org.), Direito e justiça, a função social do Judiciário, São Paulo, Ática.

SANTOS, Boaventura de Souza. (1988), O discurso e o poder: ensaio sobre a sociologia da retórica jurídica. Porto Alegre, Fabris.

(1989a), "Introdução à sociologia da administração da justiça”, in J. E. Faria (org.), Direito e justiça, a função social do Judiciário. São Paulo, Ática.

(1989b), "Justiça popular, dualidade de poderes e estratégia socialista”, in J. E. Faria (org.), Direito e justiça, a função social do Judiciário. São Paulo, Ática.

- (2007), Renovar a teoria crítica e reinventar a emancipação social. São Paulo, Boitempo.

(2008), Para uma revolução democrática da justiça. 2. ed. São Paulo, Cortez.

SABREN. (2010), "Sistema de Assentamentos de Baixa Renda (Sabren)". Banco de dados da prefeitura da cidade do Rio de Janeiro. Disponível em <http://portalgeo.rio.rj.gov.br/sabren/ index.HTM>. Acesso em 10 jul. 2009.

STROZENBERG, Pedro. (org.) (2001), Balcão de Direitos: resolução de conflitos em favelas do Rio de Janeiro: imagens e linguagens. Rio de Janeiro, Mauad. 
VALLADARES, Lícia do Prado. (2005), A invenção da favela: do mito de origem a favela.com. Rio de Janeiro, FGV.

VARELLA, Drausio. (2002), "Maré, vida na favela”, in D. Varela (org.), Falas da maré. Rio de Janeiro, Casa da Palavra.

VERBICARO, Loiane Prado. (2008), "Um estudo sobre as condições facilitadoras da judicialização da política no Brasil”. Revista Direito $G V$, 4 (2): 389-406.

VIAL, Adriana; CAVALLIERI, Fernando. (2009), "O efeito da presença governamental sobre a expansão horizontal das favelas do Rio de Janeiro: os Pouso's e o Programa Favela-Bairro”. Rio de Janeiro, Instituto Pereira Passos, Prefeitura da Cidade do Rio de Janeiro, n. 20090501: 1-11.

VIANNA, Luiz Werneck. (1999), A judicialização da política e das relaçôes sociais no Brasil. Rio de Janeiro, Revan.

VIVA-RIO. (2010), "A favela tem memória". Disponível em <http://www.favelatemmemoria.com.br/publique/cgi/cgilua.exe/sys/start. htm? sid=5\&infoid=26>. Acesso em 1 nov. 2010.

ZALUAR, Alba \& ALVITO, Marcos. (1999), "Introdução”, in A. Zaluar \& M. Alvito (orgs.), Um século de favela. Rio de Janeiro, FGV 


\section{ACESSO INDIVIDUAL E COLETIVO DE MORADORES DE FAVELAS À JUSTIÇA}

\author{
Rafaela Selem Moreira e Gisele \\ Cittadino
}

Palavras-chave: Acesso à Justiça; Favelas; Rio de Janeiro; Jurisprudência; TJRJ

Discutimos neste estudo a democratização do acesso de moradores de favelas cariocas ao Judiciário por meio de análise histórico-temporal e espacial de julgados cíveis do TJRJ. As análises foram realizadas sob dois enfoques: (1) do acesso - individual e coletivo ao judiciário; (2) do posicionamento dos magistrados frente às demandas propostas. Os resultados sugerem a relação entre: (1) aumento do acesso de moradores de favelas ao judiciário e melhoria dos índices de desenvolvimento social; (2) baixa incidência de demandas coletivas e tratamento omisso dispensado por magistrados a este tipo de ação; (3) falta de coerência entre as decisôes judiciais de magistrados e realidade social da favela e seus ajustes ao longo dos últimos anos; e traz (4) o questionamento de algumas crenças teóricas consolidadas sobre as principais variáveis na promoção do "acesso à justiça".

\section{INDIVIDUAL AND COLLECTIVE ACCESS TO JUSTICE TO SLUM DWELLERS}

\author{
Rafaela Selem Moreira and Gisele \\ Cittadino
}

Keywords: Access to justice; Judicial system; Jurisprudence; Slum; Rio de Janeiro.

Through historical and spatial analyses of civil causes in Rio de Janeiro's Court, the paper discusses the democratization of the access to justice for the slum dwellers. The analyses were accomplished under two approaches: (1) the individual and collective access to the judicial system; and (2) the positioning of magistrates in their decisions regarding the demands proposed by slum dwellers. The outcomes suggest a relationship between: (a) the increase in the access of slum dwellers to the judiciary and the improvement of the indexes of social development; (b) low incidence of collective demands and neglectful treatment of this kind of action by magistrates; (c) lack of consistency between judicial decisions and the social reality of the favela and the changes it underwent along the past few years. Finally, (d) they bring as well the questioning of some theoretical beliefs about the variables involved in the issue of the "access to justice".

\section{ACCÈS INDIVIDUEL ET COLLECTIF D'HABITANTS DE FAVELAS À LA JUSTICE}

\author{
Rafaela Selem Moreira et Gisele \\ Cittadino
}

Mots-clés: Accès à la justice; Favelas; Rio de Janeiro; Jurisprudence; TJRJ.

Nous abordons, dans cette étude, la démocratisation de l'accès d'habitants des favelas cariocas à la justice. L'étude est fondée sur l'analyse historique, temporelle et spatiale des décisions civiles du Tribunal de Justice de Rio de Janeiro (TJRJ). Les analyses ont été réalisées sous deux aspects : (1) celui de l'accès, individuel et collectif, au judiciaire ; (2) et celui de la position des magistrats face aux demandes proposées. Les résultats suggèrent le rapport entre : (1) l'augmentation de l'accès du nombre d'habitants de favelas à la justice et l'amélioration des indicateurs de développement social; (2) la baisse de l'incidence des demandes collectives et l'omission des magistrats dans le traitement de ce genre d'action; (3) le manque de cohérence entre les décisions judiciaires des magistrats et la réalité sociale de la favela et de ses adaptations au cour des dernières années; et propose (4) le questionnement de certaines croyances théoriques consolidées sur les principales variables de la promotion dans "l'accès à la justice". 